\title{
Hydrocephalus in vein of Galen malformation. Another paradigm shift in neurosurgery
}

\author{
Domenico d'Avella $^{1}$ - Francesco Causin ${ }^{2}$
}

Received: 30 April 2016/Accepted: 4 May 2016/Published online: 23 May 2016

(C) Springer-Verlag Wien 2016

The timely and due article by Meila et al. [1] addresses a topic of definite neurosurgical interest that, surprisingly, has been somehow neglected in the current neurosurgical literature. The aim of the article was to assess the evolution of treatment options for hydrocephalus in vein of Galen malformation (VGM) over the last few decades, with a particular emphasis on the dangerous implications of the old paradigm " $u b i$ hydrocephalus ibi shunt".

The vein of Galen is a short midline venous structure resulting from the confluence of the two internal cerebral veins and the basal vein of Rosenthal. It represents the caudal relic of the median prosencephalic vein, a centrally located vessel draining the choroid plexus. Malformations of the Galenic vein are believed to result from a dysembryogenic event involving the cerebral vasculature at between 6 and 11 weeks of gestation [2]. Although rare, VGM accounts for an estimated $30 \%$ of all paediatric vascular anomalies [3]. VGM can have different clinical manifestations, in relation to the entity of the hydrodynamic changes in the venous and cerebrospinal fluid (CSF) compartments that they determine or to their mass effect. The shunt from cerebral arteries into a dilated vein of Galen can lead to an increased cardiac output and finally to heart failure. This scenario is more frequent in newborns. In infants and toddlers, the chief symptom associated with the presence of a VGM is ventricular dilation,

Domenico d'Avella

domenico.davella@unipd.it

1 Academic Neurosurgery, Department of Neurosciences, University of Padova Medical School, Via Giustiniani, 235139 Padova, Italy

2 Neuroradiology, Azienda Ospedaliera, Padova, Italy leading to hydrocephalus and macrocrania. Actually, obstructive or communicating hydrocephalus is present in a significant number of patients.

Noncommunicating hydrocephalus results from obstruction of the aqueduct of Sylvius by the mass effect of the aneurysmatic dilation of the VGM. Communicating hydrocephalus is thought to be due to venous hypertension coupled to impaired CSF dynamics.

In adults, the development of hydrocephalus as a late manifestation of VGM may be due to obstruction of the cerebral aqueduct as a direct or indirect effect of the aneurysmal mass, communicating hydrocephalus after a subarachnoid haemorrhage, a dual mechanism (aqueduct obstruction and defective absorption of CSF), passive ex vacuo hydrocephalus, thrombosis of an aneurysm, and high venous pressure [4]. In this context, we reported the first case of hydrocephalus due to an aneurysm of the vein of Galen treated with an endoscopic third ventriculostomy, the rationale of the treatment being the aqueductal blockage of the CSF [2]. Although exceptionally rare, this diagnosis in adults may become more common as imaging techniques diffuse, and the role of endoscopy in the treatment of HVG deserves further assessment.

The prognosis for children harbouring these lesions has significantly improved over the last 3 decades: due to refinements in interventional endovascular techniques, it is now possible to obliterate the malformation with excellent results. Figures from the comprehensive literature review of Khullar et al. [3] indicate that as many as $84 \%$ of children treated by endovascular techniques after the turn of this century may experience a good or fair outcome. These progresses are also related to the development of integrated management protocols based on modern prenatal, neurointensive, and neuroanaesthesiological care [5]. In parallel with the improvement of overall treatment, our understanding of the 
pathophysiology of HVG has evolved, and the hydrodynamic concept of HC associated with VGM is nowadays widely accepted.

However, while the management paradigm of integrated management and endovascular obliteration of the VGM is firmly established, its logical consequence, i.e. treatment of the concomitant hydrocephalus based on its pathophysiological implications, is less substantiated and remains the object of discussion in the neurosurgical literature.

Yet in the early 1990s, when endovascular approaches evolved as the gold standard treatment option for this disorder, a few reports were published warning about the high rate of complications associated with ventriculo-peritoneal shunting in this setting. In 1992 Schneider et al. [6] observed an as high as $70 \%$ incidence of complications, including seizures, intraventricular haemorrhage, and subdural haematoma or hygroma. Other reports were in line with these figures [7-9].
Despite these recommendations, individual case reports of ventriculo-peritoneal shunting as a major contributing factor to neurological deterioration of infants with hydrocephalus associated with VGM were still the subject of publications until recently. In 2010, Jea et al. called for the use of endovascular embolisation of the VGM to rebalance hydrovenous dynamics as the first-line option rather than directly managing the hydrocephalus by CSF diversion [10].

The paper of Meila et al. [1] illustrates the paradigm shift in the management of hydrocephalus associated with VGM, namely before and after the first decade of this century. The rationale for this breaking-off point was two-fold. First was the dismal results in children receiving ventriculo-peritoneal shunting, with the large majority of them experiencing severe post-operative complications. Second was a correct understanding of the underlying pathophysiology and the
Fig. 1 Left: MR venogram obtained at 2 months of age shows a vein of Galen malformation. Right: T1weighted MR sagittal scan demonstrates marked hydrocephalus

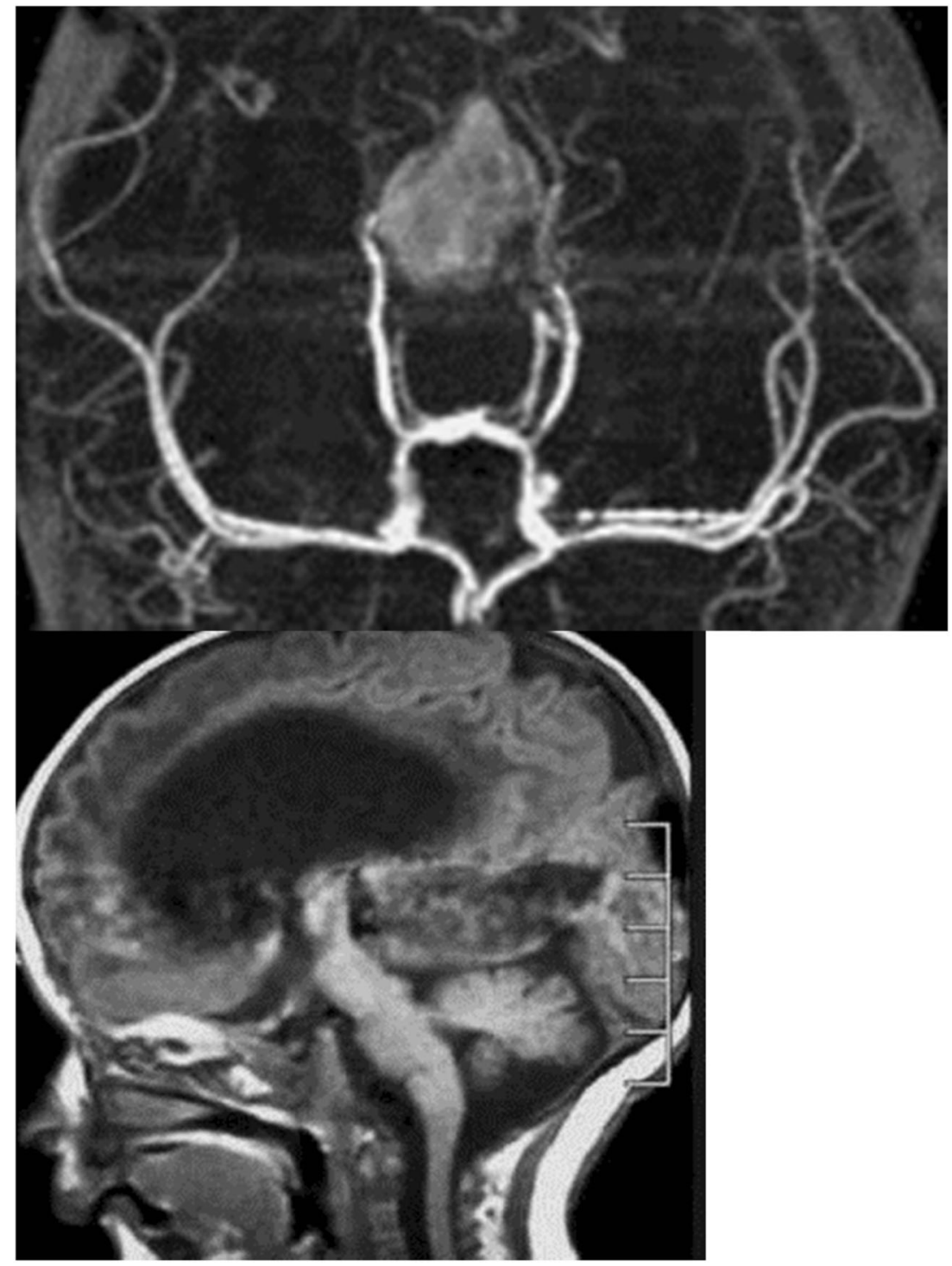


Fig. 2 a, b Antero-posterior and lateral left internal carotid DSA of the same patient with mural type VGM. c Selective microcatheter injection of a high-flow direct feeder

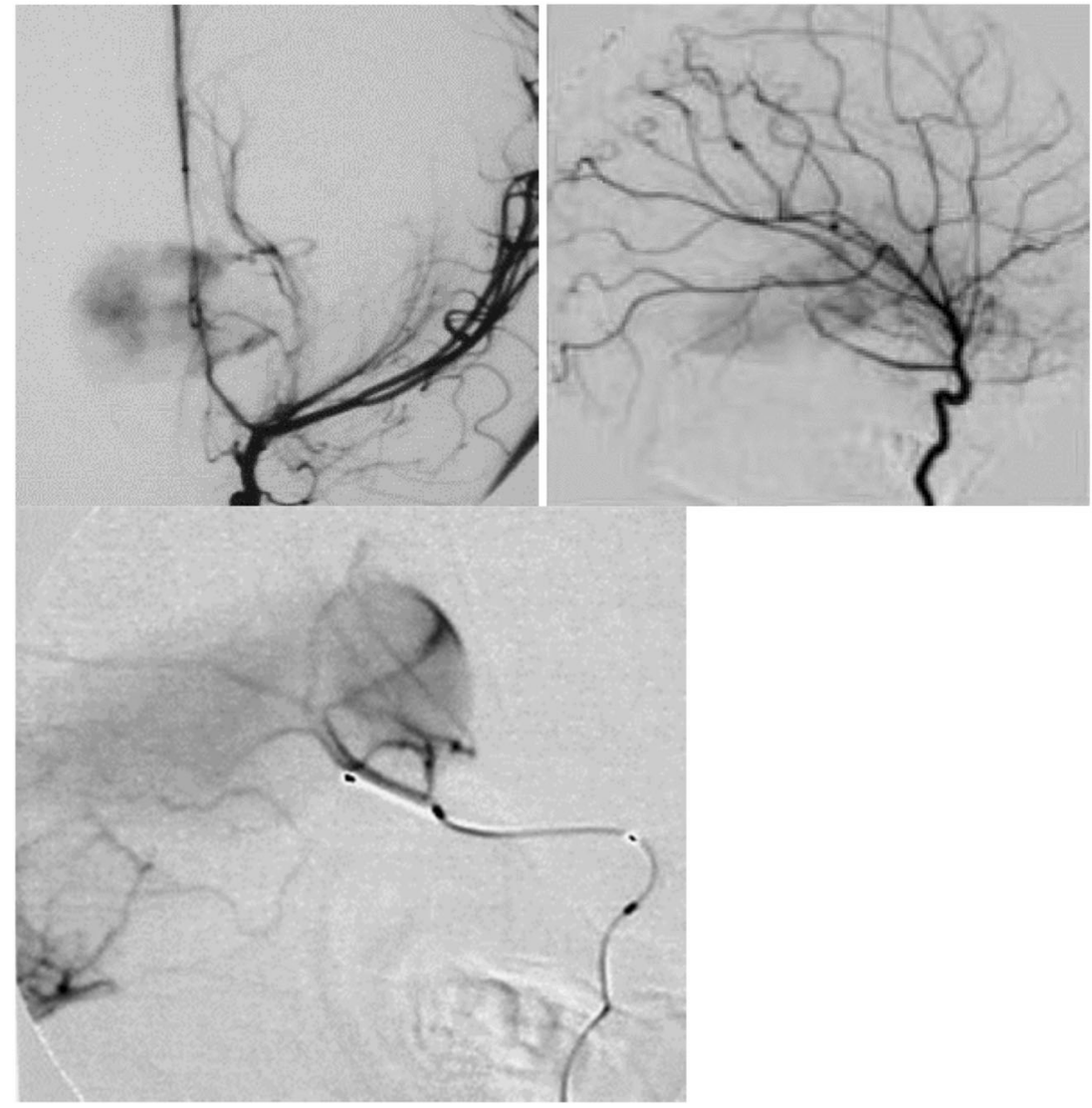

consequent recognition of embolisation of the VGM as the sole treatment sufficient to decrease high venous pressure and resolve the concomitant communicating hydrocephalus causatively.

These concepts are certainly not new to many neurosurgeons and interventional neuroradiologists dealing with this rare and demanding pathology. We share the same methodological approach and reached similar results (Figs. 1, 2, and 3). It must be recognised, however, that the paper by Meila et al.
[1] has the merit of adding exhaustive evidence to the neurosurgical literature showing that changes of ventricular size from enlarged to normal do occur after successful endovascular treatment.

It is intriguing, however, that the process of shifting the paradigm from the older to the present one (first embolise) took almost 3 decades to be completed, although technical facilities and insights into the pathophysiology of this condition were well available in the past.
Fig. 3 T1- and T2-weighted MR scans of the same patient 4 months after embolisation.

Ventricular size retuned to normal

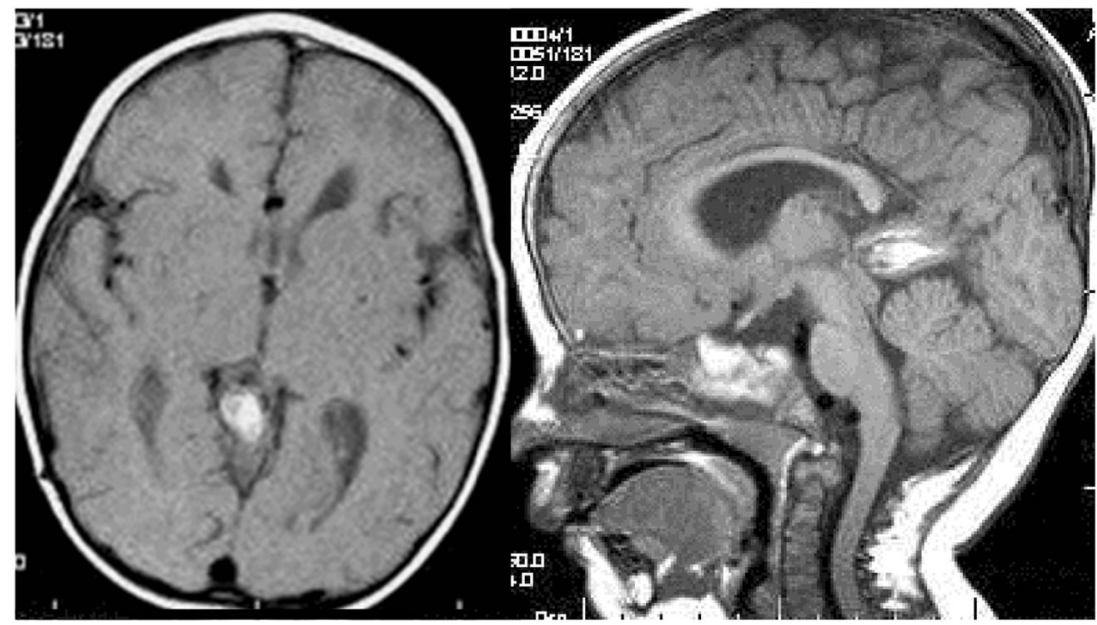




\section{References}

1. Meila d, Grieb D, Melber K, Jacobs C, Maslehety H, Pedritis A, El Habony R, Lanfermann H, Scholz M, Brasse F (2016) Hydrocephalus in vein of Galen malformation: etiologies and therapeutic management implications. Acta Neurochirurgica

2. Feletti A, Denaro L, Marton E, d'Avella D, Longatti P (2007) Endoscopic treatment of hydrocephalus due to aneurysm of the vein of Galen: case report and literature review. Minim Invasive Neurosurg 50(5):285-91

3. Khullar D, Andeejani AMI, Bulsara KR (2010) Evolution of treatment options for vein of Galen malformations. J Neurosurg Pediatr 6:444-451

4. d'Avella D, Greenberg RP, Mingrino S, Scanarini M, Pardatscher K (1980) Alterations in ventricular size and intracranial pressure caused by sagittal sinus pathology in man. J Neurosurg 53(5): 656-61

5. Berenstein A, Fifi JT, Niimi Y, Presti S, Ortiz R, Ghatan S, Rosenn B, Sorscher M, Molofsky W (2012) Vein of Galen malformations in neonates: new management paradigms for improving outcomes. Neurosurgery 70(5):1207-13, discussion 1213-4

6. Schneider SJ, Wisoff JS, Epstein FJ (1992) Complications of ventriculoperitoneal shunt procedures or hydrocephalus associated with vein of Galen malformations in childhood. Neurosurgery 30(5):706-8

7. Diebler C, Dulac O, Renier D, Ernest C, Lalande G (1981) Aneurysms of the vein of Galen in infants aged 2 to 15 months: diagnosis and natural evolution. Neuroradiology 21:185-197

8. Johnston IH, Whittle IR, Besser M, Morgan MK (1987) Vein of Galen malformation: diagnosis and management. Neurosurgery 20 : 747-757

9. Zerah M, Garcia-Monaco R, Rodesch G, Terbrugge K, Tardieu M, de Victor D, Lasjaunias P (1992) Hydrodynamics in vein of Galen malformations. Childs Nerv Syst 8:111-117

10. Jea A, Bradshaw TJ, Whitehead WE, Curry DJ, Dauser RC, Luerssen TG (2010) The high risks of ventriculoperitoneal shunt procedures for hydrocephalus associated with vein of Galen malformations in childhood: case report and literature review. Pediatr Neurosurg 46(2):141-5 